January 1973

\title{
The influence of electrical stimulation of the leg during surgical operations on the subsequent development of deep-vein thrombosis
}

\section{R Dejode}

Mohammad Khurshid

Aga Khan University, mohammad.khurshid@aku.edu

WW Walther

Follow this and additional works at: https://ecommons.aku.edu/

pakistan_fhs_mc_med_haematol_oncol

Part of the Oncology Commons

\section{Recommended Citation}

Dejode, L., Khurshid, M., Walther, W. (1973). The influence of electrical stimulation of the leg during surgical operations on the subsequent development of deep-vein thrombosis. British Journal of Surgery, 60(1), 31-32.

Available at: https://ecommons.aku.edu/pakistan_fhs_mc_med_haematol_oncol/34 


\title{
THE INFLUENCE OF ELECTRICAL STIMULATION OF THE LEG DURING SURGICAL OPERATIONS ON THE SUBSEQUENT DEVELOPMENT OF DEEP-VEIN THROMBOSIS
}

\author{
BY L. R. DEJODE, M. KHURSHID, AND W. W. WALTHER \\ WHIPPS CROSS HOSPITAL, LONDON
}

\section{SUMMARY}

The effect of galvanic stimulation of the calf muscles during surgical operations on the development of postoperative deep-vein thrombosis was assessed using ${ }^{125}$ I fibrinogen in 64 patients over 40 years of age undergoing major surgery. Alternate legs were stimulated in alternate patients using the opposite leg as a control. No significant difference in the incidence of deep-vein thrombosis was observed either in the immediate postoperative period or later.

THE use of ${ }^{125}$ I fibrinogen in the detection of deepvein thrombosis is now a well-recognized method (Atkins and Hawkins, I965; Flanc, Kakkar, and Clarke, I968). In a clinical study Doran, White, and Drury (1970) stated that the incidence of postoperative deep-vein thrombosis can be reduced by electrical stimulation of the legs during operation. Browse and Negus (1970), using the ${ }^{125}$ I-fibrinogen method, came to a similar conclusion. Since the incidence of deep-vein thrombosis is likely to be high in elderly, debilitated, and relatively immobile patients we decided to monitor such cases by the ${ }^{125}$ I-fibrinogen method to test the contention of Doran and others (1970).

\section{MATERIALS AND METHODS}

Patients of both sexes aged 40 years or over undergoing major operations were studied. There were 22 female and $\mathbf{4 2}$ male patients and the mean age was 62 years. The operation was a major upper abdominal or thoraco-abdominal procedure in 40 patients, a major lower abdominal or pelvic in 20 , and 4 operations fell into neither category.

The method of stimulation of the calf was similar to that used by Browse and Negus (1970) and Doran and others (1970), employing brief intermittent galvanic stimulation every 2 seconds to produce forcible contraction of the calf muscles.

Each patient had one leg stimulated during his operation, the other leg serving as an unstimulated control. Alternate patients had alternate legs stimulated; 33 had their right leg stimulated and 3 I the left.

${ }^{125}$ I fibrinogen, 100 m.c., was given intravenously either just before the operation or at its completion. Thyroid uptake was blocked by I0o $\mathrm{mg}$. of potassium iodide orally 24 hours before operation and continued daily for I month. The use of the Pitman 235 Ratemeter (Kakkar, Nicolaides, Renney, Friend, and Clarke, I970) allowed both legs to be scanned in about ro minutes.

\section{RESULTS}

The total number of thrombosed legs found was 36 in 25 patients, being 39 per cent of the total number of cases.

Table I shows the distribution of deep-vein thrombosis in this study.

Table 1.-Occurrence of DeEp-vein Thrombosis in the PRESENT SERIES

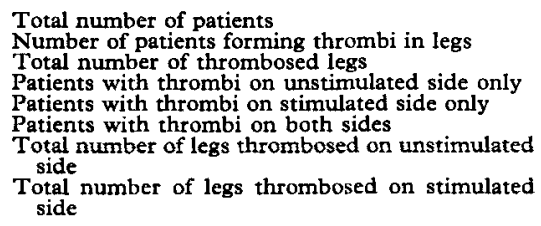

Table II.-Time of First Appearance of DeEp-vein THROMBOSIS

Time of Appearance of Thrombosis

At operation

Up to $24 \mathrm{hr}$. after operation

Up to $72 \mathrm{hr}$. after operation

Up to $9 \mathrm{~d}$. after operation

$\begin{array}{cc} & \text { No. of Patients } \\ & 3 \\ & 10 \\ & 7 \\ \text { Total } & \frac{7}{25}\end{array}$

Table III.-INCIDENCE OF DEEP-VEIN Thrombosis IN Stimulated and Unstimulated Legs in Relation to THE TIME OF ONSET AFTER OPERATION

Time after Operation

No. of Patients

Within first 24 hr.: Unstimulated

Second to ninth days: Unstimulated

10
8
9

Stimulated

Initial evidence of deep-vein thrombosis appeared during the first 9 days following operation. Table II shows the distribution in time of the occurrence of deep-vein thrombosis in patients.

Since the possible beneficial effect of leg stimulation during the operation is likely to decrease rapidly with the passage of time we have particularly noted those cases where the deep-vein thrombosis was diagnosed within 24 hours of operation. Table III shows the distribution of thrombosis between stimulated and unstimulated legs in relation to the length of time after the operation.

\section{DISCUSSION}

The possibility of reduction of postoperative deepvein thrombosis by the use of calf stimulation is based on the view that thrombosis begins during operation in the majority of cases (Doran and White, I967). 
Our results show that thrombosis was detected in 13 patients in the period between operation and up to 24 hours afterwards whereas in 12 patients this occurred between the second and ninth days. In the latter group the later onset of deep-vein thrombosis would not be expected to be prevented by the use of calf stimulation and is presumably due to factors acting in the postoperative period. It is perhaps significant that our series included a high proportion of elderly, frail patients undergoing very extensive surgery, and in these cases early mobilization was obviously limited or impossible.

These are, however, the very patients most at risk from deep-vein thrombosis and this accords with our overall incidence of deep-vein thrombosis of 39 per cent. Browse and Negus (1970), on the other hand, report a lower incidence of 23 per cent, but no patient in their series had any serious blood-loss or hypotension during or after surgery and most were active within 2 or 3 days.

The evidence for the efficacy of calf stimulation in preventing deep-vein thrombosis should be looked for in the group of patients who developed deep-vein thrombosis during operation or in the first 24 hours after operation. In the 3 patients in our series who developed deep-vein thrombosis during operation this occurred in the stimulated leg in the first, in the unstimulated leg in the second, and in both legs in the third. The distribution of thrombosis between stimulated and unstimulated legs in the first 24 hours after operation does not confirm the value of stimulation; as expected, there is no difference between the groups in the period after 24 hours.

The explanation of the conflict between our failing to demonstrate the protective effect of calf stimulation and the beneficial effect observed by Browse and Negus (1970) may be due to our agreed deliberate selection of cases in whom the likelihood of deepvein thrombosis was very great. Thus, it may be that in the ro patients who developed deep-vein thrombosis in the first 24 hours after operation any protective effect of calf stimulation was obscured by the early onset of deep-vein thrombosis in the immediate postoperative period when calf stimulation had ceased and the venous return was still slowed after the long operation and anaesthetic.

On the basis of our results we cannot conclude that stimulation of one leg during operation substantially reduces postoperative deep-vein thrombosis on the stimulated side in elderly patients undergoing major surgery. It remains possible that calf stimulation reduces the risk of deep-vein thrombosis when used in routine operations in elderly patients. In such patients the increased venous return during operation may be sufficient to prevent thrombosis during operation and rapid postoperative mobilization may prevent subsequent thrombosis. We would suggest, however, that in similar studies in the future ${ }^{125}$ I fibrinogen should be given and the legs scanned initially before operation and that the scan should be repeated immediately after the conclusion of the operation and again the next day, but not thereafter unless ward procedures to reduce deep-vein thrombosis are also being studied.

Acknowledgements.-We are grateful to $\mathrm{Mr}$. N. Veall, B.Sc., F.Inst.P., for the initial supply of ${ }^{125}$ I fibrinogen and for much useful advice, and to Dr. J. S. Glover of the Radiochemical Centre, Amersham, for a further supply of ${ }^{125}$ I fibrinogen used in this study. We would also like to thank Mr. E. G. Millwood, F.I.M.L.T., for technical assistance.

\section{REFERENCES}

Atkins, P., and Hawkins, L. A. (1965), Lancet, 2, I2I 7

BROWSE, N. L., and NEGUS, D. (I970), Br. med. F, 3,615.

DORAN, F. S. A., and WhITE, H. M. (1967), Br. F. Surg., $54,686$.

- - - - and Drury, M. (I970), Ibid., 57, 20.

Flanc, C., KakKaR, V. V., and Clarke, M. B. (I968), Ibid., 55, 742 .

KaKkaR, V. V., Nicolaides, A. N., RenNey, J. T. G., FrIEND, J. R., and Clarke, M. B. (I970), Lancet, I, 540. 